\title{
Evaluation of a telephone-based support group intervention for female caregivers of community-dwelling individuals with dementia
}

\author{
Laraine Winter \\ Thomas Jefferson University \\ Laura N. Gitlin \\ Thomas Jefferson University
}

Follow this and additional works at: https://jdc.jefferson.edu/carah_papers

Part of the Behavior and Behavior Mechanisms Commons

Let us know how access to this document benefits you

\section{Recommended Citation}

Winter, Laraine and Gitlin, Laura N., "Evaluation of a telephone-based support group intervention for female caregivers of community-dwelling individuals with dementia" (2006). Center for Applied Research on Aging and Health Research Papers. Paper 13.

https://jdc.jefferson.edu/carah_papers/13

This Article is brought to you for free and open access by the Jefferson Digital Commons. The Jefferson Digital Commons is a service of Thomas Jefferson University's Center for Teaching and Learning (CTL). The Commons is a showcase for Jefferson books and journals, peer-reviewed scholarly publications, unique historical collections from the University archives, and teaching tools. The Jefferson Digital Commons allows researchers and interested readers anywhere in the world to learn about and keep up to date with Jefferson scholarship. This article has been accepted for inclusion in Center for Applied Research on Aging and Health Research Papers by an authorized administrator of the Jefferson Digital Commons. For more information, please contact: JeffersonDigitalCommons@jefferson.edu. 


\section{Evaluation of a Telephone-Based Support Group Intervention for Female Caregivers of Community-Dwelling Individuals With Dementia}

Laraine Winter and Laura N. Gitlin

From the Center for Applied Research in Aging and Health, Thomas Jefferson University, Philadelphia, Pennsylvania.

The research reported in this article was supported by funds from the Alzheimer's Association awarded to Laura N. Gitlin, PhD.

Address correspondence to: Laura N. Gitlin, PhD, Director, Center for Applied Research on Aging and Health, Thomas Jefferson University, 130 South 9th Street, Suite 513, Philadelphia, PA 19107.

Family caregivers, the "second victims" or hidden patients in dementia care, are at risk for social isolation, stress, depression, and mortality. Telephone-based support (telesupport groups) represents a practical, low-burden, low-cost source of emotional support. The present study evaluated the feasibility and effectiveness of professionally led telephone-based support groups for female family caregivers of community-dwelling dementia patients. Recruited through various community sources, 103 female caregivers were randomized to the telesupport group treatment or a control condition. Effects on caregiver burden, depression, and personal gains were evaluated at 6 months, the main end point. Older caregivers $(\geq 65)$ in telesupport reported lower depression than control group caregivers did.

Keywords: Alzheimer's disease; caregiving, support groups

This is the author's final version prior to publication in The American Journal of Alzheimer's Disease and Other Dementias 21(6):391, December 2006. The published version is available at http://aja.sagepub.com/cgi/content/abstract/21/6/391, DOI: 10.1177/1533317506291371 
Family caregivers are the "second victims" or hidden patients in dementia care ${ }^{1}$ who under-utilize services. ${ }^{2}$ As caregiving demands escalate with disease progression, caregivers are increasingly at risk for social isolation, stress, depression, sleep deprivation, and mortality. ${ }^{3}$ Given that there are close to 5 million persons with Alzheimer's disease or related disorders (ADRD) and that this number is expected to increase substantially, ${ }^{4}$ there is a critical need to develop and rigorously test practical, cost-effective services that improve life quality of families from diverse ethnic, racial, and socioeconomic groups. As suggested by stress process theory ${ }^{5}$ and previous caregiver research, providing emotional support to families may buffer the emotional and social consequences of caregiving.

Support groups have been widely promoted to reduce the social isolation that often attends caregiving. ${ }^{7-13}$ Yet for some caregivers, caregiving demands or inadequate time or transportation make it difficult to attend face-to-face group meetings. For such caregivers, telephone-based groups may provide much-needed emotional support. ${ }^{14,15}$ Providing support by telephone places minimal burden on caregivers. It is well suited to individuals who are homebound with limited time and energy to seek formal supportive services. Such an intervention also may appeal to persons who are not inclined to join face-to-face support programs or seek formal help.

This is the author's final version prior to publication in The American Journal of Alzheimer's Disease and Other Dementias 21(6):391, December 2006. The published version is available at http://aja.sagepub.com/cgi/content/abstract/21/6/391, DOI: 10.1177/1533317506291371 
The present study evaluates the feasibility and effectiveness of professionally led telephone-based support groups (telesupport groups) to increase social support and reduce depression and burden among white and African American female caregivers of persons with ADRD. The intervention, which provides emotional support, is practical and low cost.

Despite recent advances in telemedicine, the telephone as a therapeutic modality with family caregivers has not been tested. Previous research demonstrated its feasibility to provide information, enhance skills, and link caregivers for peer support. $^{15-17}$ Studies were limited, however, by small sample sizes and lack of true control groups. One exception, the Miami REACH intervention, used teleconferencing to link families as an adjunct to family therapy and found reduced caregiver depression. ${ }^{18}$ That work also established the value, feasibility, and usability of telephone supports in both English- and Spanish-speaking caregivers. ${ }^{19}$ Nevertheless, the effectiveness of telesupport has not been evaluated using randomized controlled designs.

This study was a collaboration between a service organization, Supportive Older Women's Network, and an academic research center. A randomized, controlled, 2group design with 103 female caregivers tested the effectiveness of the intervention at 6 months to alleviate depression and burden and enhance a sense of personal gains. Secondary study aims evaluated the relative benefits for younger versus older Disease and Other Dementias 21(6):391, December 2006. The published version is available at http://aja.sagepub.com/cgi/content/abstract/21/6/391, DOI: 10.1177/1533317506291371 
women and for African American versus white women and assessed the relationship between intervention exposure (dose) and benefits. Differential treatment effects by age group were explored given that older female caregivers experience greater distress than younger caregivers because of their own increasing physical vulnerabilities.

\section{Method}

\section{Participants}

One hundred three female caregivers were recruited through targeted mailings to adult day center users, clinical programs, and newspaper display ads. Eligibility criteria were being female, 50 years of age or older, providing care for a minimum of 6 months to a relative with a physician's diagnosis of ADRD, and having weekly access to a telephone for at least 1 hour. Only female caregivers were recruited because women represent most of those providing care and consistently demonstrate significantly more stress and negative health outcomes than male caregivers do. ${ }^{20}$

\section{Measures}

Interviews consisted of demographic questions (age, race, relationship to care recipient, marital status, occupation, years of education) for caregivers and care recipients. The main outcome measures were depression, burden, and personal gains.

This is the author's final version prior to publication in The American Journal of Alzheimer's Disease and Other Dementias 21(6):391, December 2006. The published version is available at http://aja.sagepub.com/cgi/content/abstract/21/6/391, DOI: 10.1177/1533317506291371 
Caregiver depression was measured using the 20-item Centers for Epidemiological Studies - Depression Scale (CES-D). ${ }^{21}$ The response format for each item is 0 (never or rarely) to 4 (always). Scores were summed, with higher scores indicating greater depression and a score of 16 or higher indicative of depressive symptoms ${ }^{22}$ (Cronbach's $\alpha=.88$ ).

Caregiver burden was measured by the 22-item Zarit burden scale ${ }^{22}$ (eg, "Do you feel you have lost control of your life since your relative's illness?"). For each item, caregivers report the extent of agreement on a scale ranging from 0 (never) to 4 (always). The last item is, "Overall, how burdened do you feel in caring for your relative?" with a response format from 0 (not at all) to 4 (extremely). Responses were summed to produce a total score ranging from 0 to 88 , with high scores indicating greater burden (Cronbach's $\alpha=.87$ ).

Gains were measured with a 6-item scale adapted from Kaye's ${ }^{10}$ Gain Through Group Involvement Scale to assess the extent to which caregivers perceive personal gains over the past few months in new friendships, knowing what to do when lonely, how to handle the blues, how to handle stress, how to find health care or other resources, and ability to deal with family relationships. Responses to each item were not at all (1), a little (2), or a great deal (3). The sum of the 6 items was calculated, yielding a possible range from 6 to 18 . The actual range was 7 to 18 (Cronbach's $\alpha=$ $.80)$.

This is the author's final version prior to publication in The American Journal of Alzheimer's Disease and Other Dementias 21(6):391, December 2006. The published version is available at http://aja.sagepub.com/cgi/content/abstract/21/6/391, DOI: 10.1177/1533317506291371 


\section{Procedure}

Caregivers who contacted the research office were provided with an explanation of the study and screened for eligibility by telephone. Eligible caregivers who agreed to participate consented orally using an approved Institutional Review Board statement and were administered a 30-minute interview, also by telephone. Following the interview, participants were randomly assigned to intervention or control. The Supportive Older Women's Network was notified of caregivers randomized to intervention and contacted caregivers to enroll them in a group. Control subjects were sent a letter describing their group assignment and the next study steps.

Six months from baseline, all subjects were reassessed by telephone.

\section{Intervention}

Telesupport groups were conducted by trained social workers who used conferencecalling technology (Toshiba Digital Business Telephone Model DKT2010-S System and Centrex teleconference service) to link 5 caregivers per group for an hour weekly. Caregivers used their own telephones with no charge. The primary goal was to enhance caregiver ability to manage daily stressors by providing emotional support and validation. Initially, facilitators focus on developing group cohesion. As groups progress, disclosure of intimate problems and personal conflicts emerge. Caregivers express emotions and share coping strategies including cognitive 
reframing and practical approaches to organizing care routines. They also assist each other in problem solving and share educational resources. The mutual support and validation provided by group members normalize experiences and provide a supportive social network, core to the service model.

\section{Statistical Methods}

A sample size of 100 was required for at least $80 \%$ power to detect a large effect size of $0.70^{23}$ with adjustment for cluster randomization. ${ }^{24}$ Caregivers randomized to treatment and control groups were first compared on demographic variables and the baseline values for the outcome variables using $x^{2}$ and Wilcoxon rank-sum tests, as appropriate. The distribution of the residuals was expected to be skewed, owing to the homogeneity of the sample (older women). For this reason, a nonparametric test of group differences was used.

For each primary outcome (burden, depression, and gains), a linear mixed models analysis of covariance (ANCOVA) was performed. Treatment assignment and age group (younger than 65 vs 65 or older) served as independent variables, with race as a covariate. Age group was entered as an independent variable. Because age and spousal relationship are associated, a post hoc ANCOVA was conducted substituting spousal relationship (wife or other) as the independent variable. To represent the cluster variable, each support group was assigned a number (1-9). Caregivers randomized to intervention but who did not participate in 
any group session were assigned to group 0 . Controls were also assigned to dummy groups based on date of study entry (groups 10-19). Group (0-19) was then entered as a random effect to control for potential variability between groups that may affect outcomes. In each model, the baseline value of the dependent variable was entered as a covariate.

Next, we examined the relationship between number of sessions attended and outcomes for intervention caregivers. Multiple regression analyses were used, relating each outcome to the number of sessions in which caregivers participated (session participation). Demographic characteristics, baseline depression score, and group number as random effects were also entered into the regression models as predictors.

Finally, predictors of participation in telesupport sessions was evaluated using a linear mixed model in which the total number of sessions attended was regressed on demographic characteristics, mood at baseline, and relationship to care recipient.

\section{Results}

\section{Sample Characteristics}

Fifty-eight female caregivers were randomized to treatment and 45 to usual care (control). For the total sample, caregivers' mean age was 66.6 years $(S D=9.1$; range, 51-86); 68.3\% were white, and the remaining caregivers were African American. Most were educated beyond high school (51.0\%), 35.6\% were high

This is the author's final version prior to publication in The American Journal of Alzheimer's Disease and Other Dementias 21(6):391, December 2006. The published version is available at http://aja.sagepub.com/cgi/content/abstract/21/6/391, DOI: 10.1177/1533317506291371 
school graduates, and $10.6 \%$ had less than 12 years of education. Wives constituted $57.7 \%$ of the sample. The average depression score on the CES-D at baseline was $15.1(S D=11.0$; range, $0-49)$, slightly less than the cutoff score of 16 for depressive symptoms.

The treatment and control groups were compared on demographic characteristics and baseline values of the outcome measures. Those randomized to the experimental group were significantly older than those in the control group. Control group subjects scored slightly higher than the treatment group on gains. Table 1 presents means for each group and the differences between them at baseline.

\section{Intervention Participation}

Telesupport group caregivers participated in an average of $14.8(S D=10.7$; range, 0-26) sessions, of a possible 26 in the 6 months following baseline. Ninety-four caregivers (91.3\%) were available for the 6-month telephone interview. Among these, 81 were still caregiving at home; the remaining had placed their relatives in nursing facilities or were bereaved.

\section{Six-Month Intervention Effects}

Table 2 presents means and standard deviations for depressed affect, caregiver burden, and gains for younger (50-64 years of age) and older (65 or older) caregivers, along with results for main treatment effects and interaction of treatment

This is the author's final version prior to publication in The American Journal of Alzheimer's Disease and Other Dementias 21(6):391, December 2006. The published version is available at http://aja.sagepub.com/cgi/content/abstract/21/6/391, DOI: $10.1177 / 1533317506291371$ 
by age group. There were no large or statistically significant differences between experimental and control group participants at 6 months on the outcome measures. While all caregivers scored high in depression, older caregivers in the telesupport group scored 4 points lower than older caregivers in the control group did, suggesting more benefit for this age group. Race was not found to be associated with any 6-month outcomes $(F[1]<0.127, P<.25)$, nor did race interact with treatment effect.

Because wives are usually older than other care-giving relatives, we tested whether spousal relationship might account for the age group effect. The mixedmodel ANCOVA substituting spousal relationship for age found a significant main effect for depression such that wives were more depressed than other relatives were, $F(1,90)=4.348, P=.040$. However, we did not find a significant interaction between spousal relationship and treatment, $F(1,90)=0.757, P=.387$. Thus, the effect appears to be attributable to age and not spousal relationship.

\section{Dose-Response Analysis and Predictors of Session Attendance}

How did the amount of participation affect treatment outcomes for those receiving telesupport? Session attendance was not found to be associated with depression, caregiver burden, or gains at 6 months. Age, caregiver relationship to care recipient, and race were associated with the number of telesupport sessions attended by 6 months, as revealed by the mixed-method analysis. Older caregivers participated in 
fewer sessions than younger ones did. Wives participated in more sessions than other relatives did (16.7 compared to 11.8; $F[1]=5.56, P=.022$ ), and African Americans participated in more sessions than whites did (15.9 vs $14.4 ; F[1]=3.84$, $P=.056$; see Table 3). Depressed affect at baseline did not predict session participation.

\section{Discussion}

Overall, these results argue for minimal benefits of support group participation and only for older women (those 65 or older) caring for a relative with ADRD. In comparison to control group participants, older telesupport group participants reported reduced depression at 6 months. In addition, gains showed a marginal interaction with age, also favoring the older group. Of interest is that dose or amount of exposure to the intervention was not related to treatment outcomes, suggesting that even minimal participation may have some benefit for some participants. Also, although telesupport appeared to be an acceptable intervention for white and African American caregivers, the latter group had higher participation rates. Similarly, older women participated in fewer sessions than younger ones did, despite the fact that the older women showed greater benefit from the intervention, as least in depression. This suggests that special efforts should be directed at encouraging women 65 or older to participate in group sessions.

Why older caregivers benefited more than younger ones is not clear. Older caregivers were not more depressed than younger ones at baseline; in fact, a post

This is the author's final version prior to publication in The American Journal of Alzheimer's Disease and Other Dementias 21(6):391, December 2006. The published version is available at http://aja.sagepub.com/cgi/content/abstract/21/6/391, DOI: 10.1177/1533317506291371 
hoc Pearson product-moment correlation showed that age and depression were negatively associated $(r=-0.23, P=.021)$. It is possible that older caregivers were more isolated and had a greater need for the social interaction provided by the group in comparison to younger counterparts. This is a question for future research.

In addition, it is important to note that the measures used in this study to evaluate the impact at 6 months may not fully capture the benefits of group participation. Interventionists and many caregivers anecdotally reported that the support groups helped caregivers get through their day and gave them something to look forward to. Also, at least 2 support groups have continued to meet after completion of this study even though some care recipients died. This, too, reflects on the strength of perceived intervention benefits for at least some participants.

Although professionally led telesupport groups have some benefit for older women, there are numerous challenges associated with implementing this intervention. One difficulty is recruiting enough caregivers to initiate a support group in a timely manner. Recruiting and enrolling for a study of stressed and burdened population such as dementia caregivers are difficult. In addition, developing compatible groups makes it especially difficult since, once screened, caregivers may need to wait weeks to months for the enrollment of other participants and a group to be formed. In this study, caregivers' complicated scheduling needs and limited availability posed a difficulty for timely group formation. Before a group was formed, at least three caregivers had to be available for the same hour weekly. This required Disease and Other Dementias 21(6):391, December 2006. The published version is available at http://aja.sagepub.com/cgi/content/abstract/21/6/391, DOI: 10.1177/1533317506291371 
enrolling a substantial number of caregivers simultaneously, an inherent difficulty as well if implementing the intervention in a service context.

The study was also limited by a small sample size and exclusion of ethnic groups and male caregivers. Future research should expand the demographic range and sample size. Finally, we did not conduct a cost analysis, but telesupport appears to be relatively cost-efficient, with costs estimated to be $\$ 28.50$ per person per session for coordination assistance, group facilitation, and telephone charges. Over the course of the intervention, it may be possible to develop peer-based leaders to continue the groups without professional expenditure.

Despite these limitations, the results argue for some benefit for older women and the appeal of this approach for underserved populations (African Americans) and wives, who experience greater upset and depression than other caregiving relatives. Telesupport should be available for caregivers particularly at the moderate disease stage, an especially stressful and isolating period. It is unclear how to adjust the intervention to encourage white and caregiver daughters to participate, since these groups seem not to attend as consistently as others do, even though they are as likely to benefit.

In conclusion, telesupport is an untapped but feasible modality. Further research is required to evaluate cost, dose-response relationships, other approaches (eg, counseling) that use this technology and who benefits most and why.

This is the author's final version prior to publication in The American Journal of Alzheimer's Disease and Other Dementias 21(6):391, December 2006. The published version is available at http://aja.sagepub.com/cgi/content/abstract/21/6/391, DOI: 10.1177/1533317506291371 


\section{Acknowledgment}

The authors gratefully acknowledge the significant contributions of the interventionists, Patricia Davis, MSW; Marypat Tracey, MSW; Carolyn Schneider, BA; SOWN director Merle Drake, MSS; and Nancy Morrow, MSW.

\section{References}

1. Ory MG, Hoffman RR III, Yee JL, Tennstedt S, Schulz R. Prevalence and impact of caregiving: a detailed comparison between dementia and nondementia caregivers. Gerontologist. 1999;39:177-185.

2. Brodaty H, Thomson C, Thompson C, Fine M. Why caregivers of people with dementia and memory loss don't use services. Int J Geriatr Psychiatry. 2005;20:537-546.

3. Schulz R, Beach SR. Caregiving as a risk factor for mortality: the caregiver health effects study. JAMA. 1999; 282:2215-2219.

4. Ferri CP, Prince M, Brayne C, et al. Global prevalence of dementia: a delphi consensus study. Lancet. 2005;366: 2112-2117.

5. Pearlin LI, Mullan JT, Semple SJ, Skaff MM. Caregiving and the stress process: an overview of concepts and their measures. Gerontologist. 1990;30:583-594.

6. Mittelman MS, Ferris SH, Shulman E, Steinberg G, Levin B. A family intervention to delay nursing home placement of patients with Alzheimer

This is the author's final version prior to publication in The American Journal of Alzheimer's Disease and Other Dementias 21(6):391, December 2006. The published version is available at http://aja.sagepub.com/cgi/content/abstract/21/6/391, DOI: 10.1177/1533317506291371 
disease: a randomized controlled trial. JAMA. 1996;276:1725-1731.

7. Cuijpers P, Hosman CM, Munnichs JM. Change mechanisms of support groups for caregivers of dementia patients. Int Psychogeriatr. 1996;8:575587.

8. Greene VL, Monahan DJ. The effect of a support and education program on stress and burden among family caregivers to frail elderly persons. Gerontologist. 1989; 29:472-477.

9. Haley WE. Group intervention for dementia family caregivers: a longitudinal perspective. Gerontologist. 1989; 29:478-480.

10. Kaye LW. Assessing the efficacy of a self-help support group program for older women. Journal of Women and Aging. 1995;7:11-30.

11. Montgomery RJ, Borgatta EF. The effects of alternative support strategies on family caregiving. Gerontologist. 1989;29:457-464.

12. Toseland RW, Rossiter CM. Group interventions to support family caregivers: a review and analysis. Gerontologist. 1989;29:438-448.

13. Toseland RW, Rossiter CM, Labrecque MS. The effectiveness of peer-led and professionally led groups to support family caregivers. Gerontologist. 1989;29:465-471.

14. Galinsky MJ, Schopler JH, Abell MD. Connecting group members through telephone and computer groups. Health Soc Work. 1997;22:181-188.

15. Martindale-Adams J, Nichols LO, Burns R, Malone C. Telephone support groups: a lifeline for isolated Alzheimer's disease caregivers. Alzheimer's

This is the author's final version prior to publication in The American Journal of Alzheimer's Disease and Other Dementias 21(6):391, December 2006. The published version is available at http://aja.sagepub.com/cgi/content/abstract/21/6/391, DOI: 10.1177/1533317506291371 
Care Quarterly. 2002;3:181-189.

16. Davis LL. Telephone-based interventions with family caregivers: a feasibility study. Journal of Family Nursing. 1998;4:255-270.

17. Goodman CC, Pynoos J. Telephone networks connect caregiving families of Alzheimer's victims. Gerontologist. 1988;28:602-605.

18. Eisdorfer C, Czaja SJ, Loewenstein DA, et al. The effect of a family therapy and technology-based intervention on caregiver depression. Gerontologist. 2003;43: 521-531.

19. Bank AL, Arguelles S, Rubert M, Eisdorfer C, Czafa SJ. The value of telephone support groups among ethnically diverse caregivers of persons with dementia. Gerontologist. 2006;46:134-138.

20. Yee JL, Schulz R. Gender differences in psychiatric morbidity among family caregivers: a review and analysis. Gerontologist. 2000;40:147-164.

21. Radloff LS. The CES-D scale: a self-report depression scale for research in the general population. Applied Psychological Measurement. 1977;1:385-401.

22. Bedard M, Molloy DW, Squire L, Dubois S, Lever JA, O'Donnell M. The Zarit burden interview: a new short version and screening version. Gerontologist. 2001;41:652-657.

23. Cohen J. Statistical Power Analysis for the Behavioral Sciences. Hillsdale, NJ: Lawrence Erlbaum Associates; 1988.

24. Hauck WW, Gilliss CL, Donner A, Gortner S. Randomization by cluster. Nurs Res. 1991;40:356-358.

This is the author's final version prior to publication in The American Journal of Alzheimer's Disease and Other Dementias 21(6):391, December 2006. The published version is available at http://aja.sagepub.com/cgi/content/abstract/21/6/391, DOI: 10.1177/1533317506291371 
Table 1. Baseline Differences Between Experimental and Control Participants

\begin{tabular}{|c|c|c|c|c|c|}
\hline & $\begin{array}{l}\text { Experimental } \\
(\mathrm{n}=58)\end{array}$ & $\begin{array}{l}\text { Control } \\
(n=45)\end{array}$ & $x^{2}$ & Z & $\mathrm{P}$ \\
\hline \multicolumn{6}{|l|}{ Caregiver characteristics } \\
\hline Age, y & $68.7(9.3)$ & $64.0(8.2)$ & & -2.38 & .017 \\
\hline Race, \% African American & 27.6 & 33.3 & 0.398 & & .528 \\
\hline Years of education, \% & & & 0.303 & & .859 \\
\hline$<$ High school & 12.3 & 8.9 & & & \\
\hline High school & 36.8 & 37.8 & & & \\
\hline$>$ High school & 50.9 & 53.3 & & & \\
\hline Relationship to care recipient, \% spouse & 34.5 & 48.9 & 2.18 & & .140 \\
\hline Economic well-being & $1.9(1.0)$ & $2.2(1.1)$ & & -1.02 & .307 \\
\hline Years of caregiving & $4.2(3.6)$ & $4.6(4.6)$ & & -0.054 & .957 \\
\hline \multicolumn{6}{|l|}{ Caregiver outcomes } \\
\hline CES-D & $15.9(11.1)$ & $14.1(10.80)$ & & -0.99 & .321 \\
\hline Gains & $12.6(2.8)$ & $13.8(2.8)$ & & -2.16 & .031 \\
\hline Burden & $33.7(14.5)$ & $35.0(15.1)$ & & -0.33 & .742 \\
\hline ADL upset & $1.3(2.2)$ & $1.2(2.3)$ & & -0.48 & .630 \\
\hline ADL self-efficacy & $1.7(0.4)$ & $1.8(0.4)$ & & -1.21 & .226 \\
\hline Memory and problem behavior upset & $9.6(7.8)$ & $10.2(8.5)$ & & -0.16 & .876 \\
\hline Memory and problem behavior self-efficacy & $1.3(0.5)$ & $1.4(0.5)$ & & -0.64 & .520 \\
\hline \multicolumn{6}{|l|}{ Care recipient characteristics } \\
\hline Age, y & $81.0(7.9)$ & $79.2(10.4)$ & & -0.642 & .521 \\
\hline Race, \% African American & 27.6 & 31.1 & 0.153 & & \\
\hline \multicolumn{6}{|l|}{$\begin{array}{l}\text { Care recipient functioning and behavior } \\
\text { (rated by caregiver) }\end{array}$} \\
\hline ADLs & $5.0(5.0)$ & $5.8(4.7)$ & & -1.06 & .289 \\
\hline Memory and problem behaviors & $9.5(4.9)$ & $10.2(4.4)$ & & -0.76 & .447 \\
\hline
\end{tabular}

CES-D = Centers for Epidemiological Studies - Depression Scale; ADL = activity of daily living.

This is the author's final version prior to publication in The American Journal of Alzheimer's Disease and Other Dementias 21(6):391, December 2006.

The published version is available at http://aja.sagepub.com/cgi/content/abstract/21/6/391, DOI: 10.1177/1533317506291371 
Table 2. Means (SD) of Depression, Burden, and Gains Scores, With ANCOVA Results at 6 Months

\begin{tabular}{|c|c|c|c|c|c|c|c|c|}
\hline & Treatment & Control & $\mathrm{F}$ & df & $P$ & $\mathrm{~F}$ & df & $P$ \\
\hline CES-D $(n=94)$ & $18.17(7.19)$ & $20.20(7.20)$ & 4.58 & 1 & .121 & 6.26 & 1 & .014 \\
\hline Younger & 20.95 (8.04) & $19.29(8.08)$ & & & & & & \\
\hline Older & $16.13(6.91)$ & $20.00(6.51)$ & & & & & & \\
\hline Caregiver burden $(n=81)$ & $31.66(15.16)$ & 31.74 (17.29) & 0.46 & 1 & .490 & 0.878 & 1 & .352 \\
\hline Younger & $33.95(15.04)$ & & & & & & & \\
\hline Older & $29.96(15.31)$ & & & & & & & \\
\hline Gains $(n=94)$ & $13.52(2.85)$ & $14.17(2.57)$ & 0.073 & 1 & .932 & 3.01 & 1 & .086 \\
\hline Younger & $12.82(3.02)$ & $14.50(2.62)$ & & & & & & \\
\hline Older & $14.03(2.65)$ & $13.72(2.49)$ & & & & & & \\
\hline
\end{tabular}

CES-D = Centers for Epidemiological Studies - Depression Scale

This is the author's final version prior to publication in The American Journal of Alzheimer's Disease and Other Dementias 21(6):391, December 2006. The published version is available at http://aja.sagepub.com/cgi/content/abstract/21/6/391, DOI: 10.1177/1533317506291371 
Table 3. Predictors of Session Attendance at 6-Month Follow-up: Multiple Regression Coefficients

\begin{tabular}{llll}
\hline Predictors & $B$ & $t$ & $P$ \\
\hline Age & -.36 & 2.19 & .005 \\
Spousal relationship (wife vs. other) & -.68 & 3.52 & .001 \\
Years of education & -.03 & 0.19 & .849 \\
Race (white vs African American) & .38 & 2.32 & .024 \\
Depression* & -.02 & 0.16 & .871 \\
\hline
\end{tabular}

${ }^{*}$ Baseline depression 
This is the author's final version prior to publication in The American Journal of Alzheimer's Disease and Other Dementias 21(6):391, December 2006. The published version is available at

http://aja.sagepub.com/cgi/content/abstract/21/6/391, DOI: 10.1177/1533317506291371 